\title{
Eram dois no mundo - o reconhecimento do outro e a metamorfose como estruturas
}

\author{
Soraya Beatriz Luciano Silva ${ }^{1}$
}

\section{Resumo}

Este texto busca realizar uma análise crítica do espetáculo Recusa, da Cia. Balagan. A partir do conceito de alteridade, pretende-se mostrar como a montagem busca deslocar o espectador de seu lugar habitual, demandando deste a disponibilidade para reconhecer o outro e não apenas a si mesmo. Isso se dá a partir do mergulho nas narrativas mitológicas ameríndias e, consequentemente, na articulação dos procedimentos da atuação, dramaturgia e encenação.

Palavras-chave: Alteridade; Mito; Espectador.

\section{Abstract}

This article pretends realize a critical analysis of the play Recusa, as staged by Cia. Balagan. Given the concept of otherness, this text tries to show how the spectacle seeks to move the viewer in his usual place, demanding this willingness to recognize others and not just yourself. This occurs from the dip in mythological narratives Amerindian and hence the joint procedures of acting, playwriting and staging.

Keywords: Otherness; Myth; Spectator.

Eram dois no mundo. Iguais, mas diferentes. Se um cantava, o outro ria; se um fazia uma planície, vinha o outro com a montanha. Quando um brincava de ser caça, caçador tornava-se o outro, em um movimento constante de abertura e reconhecimento. Duplos essenciais, míticos, que ampliam sua potência na multiplicação, e não na divisão, em um processo de deslocamento da ideia de unidade para a de alteridade: reconhecer o outro, vestir o outro e, com isso, tornar-se outro, ter o outro dentro de si. Esta é a metáfora que percorre a estruturação do discurso teatral em Recusa, espetáculo da Cia. Balagan, com direção de Maria Thaís.

A montagem é fruto de mais de três anos de pesquisa e, de acordo com a diretora, uma notícia de jornal, sobre a "descoberta" de dois índios pertencentes a uma tribo já dada como extinta que haviam permanecido durante anos isolados em meio à

1 Soraya Beatriz é mestranda do Programa de Pós-graduação em Artes da Escola de Belas Artes da Universidade Federal de Minas Gerais, jornalista e crítica teatral. 
floresta, serviria de articulador para os conceitos que vinham sendo trabalhados pela equipe envolvida na pesquisa. "Já estávamos tendo uma aproximação com a cultura indígena, ameríndia, através do estudo de textos de antropologia”, afirma Maria Thaís².

Em suas escolhas formais, o espetáculo parece carregar de forma imanente os conceitos antropológicos que lhe serviram como um dos pontos de partida - ainda segundo a diretora, com destaque para as Mitológicas, de Lévi-Strauss, e os estudos de Eduardo Viveiros de Castro -, transformando-os não apenas em conteúdos verbais, mas, também e principalmente, em estrutura narrativa, jogo cênico, registro de atuação. Assim, na tentativa de buscar novas formas de narrar, pensar e ver o mundo, uma das consequências parece ser a ampliação da perspectiva da unidade (dramática e simbólica) em prol da alteridade do espectador, este podendo ser encarado como o outro na relação palco-plateia.

O trabalho, um dos mais premiados da atual temporada em São Paulo (incluindo Shell e APCA), recebeu a ênfase das atuações de Antonio Salvador e Eduardo Okamoto. O duo de atores - assim como se dará depois também na dramaturgia e na encenação - sintetiza em cena a constatação do antropólogo francês Claude Lévi-Strauss de que, nas culturas ameríndias, a mitologia se baseia na existência de um duplo, a presença de um par mítico em que os indivíduos, em vez de aniquilar-se, compartilham sua diferença essencial. Portanto, não me parece ser insignificante, neste caso, o fato de que, em tais premiações, pareceu sensato à comissão julgadora não repartir os louros entre um ou outro ator, mas, sim, reconhecer que um não existiria sem o outro, ou melhor, um só existe no outro; síntese da noção de alteridade.

É na relação entre os atores - tanto entre eles quanto com o material que se apropriam em cena - que se estabelece a princípio a imagem do duplo e, soma-se a essa proposição, uma outra apresentada por Eduardo Viveiros de Castro em texto reproduzido no programa da peça: “(...) o que dizem todos os mitos é que, outrora, todos os animais eram humanos, ou mais, exatamente pessoas" (...).

O "primeiro contato" com o outro (o outro entendido aqui tanto como o índio e sua cultura quanto como o espectador) se dá através e no corpo-voz dos atores, em que se concretiza esse princípio de "metamorfose" dos seres. No início do espetáculo, os

\footnotetext{
2 A autora do texto assistiu ao espetáculo em apresentação no dia $1^{\circ}$ de abril de 2013, pela programação do Festival de Curitiba, ocasião em que também entrevistou a diretora do espetáculo, Maria Thaís Lima Santos, cujos trechos foram aqui utilizados. A entrevista foi publicada na íntegra no blog Horizonte da Cena (www. horizontedacena.blogspot.com.br)
} 
atores estão dançando, cantando e brincando, falam um dialeto próprio. No espaço vazio, ora são pacas, ora as caçam. Seus corpos se transformam em outros, espeIham-se em alguns momentos, diferenciam-se em outros. Falam a língua dos homens, mas também a dos bichos. Okamoto e Salvador atingiram um grau de apropriação tão alto do material - tanto dos conceitos presentes nos textos antropológicos quanto das técnicas trabalhadas, assim como as danças e cantos no período de pesquisa que estiveram em Rondônia, com os Paiter Suruí - que não atuam no nível da representação como mimese, mas, sim, da recriação, disponibilizando seu potencial vocal e corporal para mostrarem o mundo pela perspectiva do outro; nunca no lugar do outro.

Assim como nos mitos indígenas, em que se veste a pele do outro, em que se come o outro e este passa a viver dentro de si, Okamoto e Salvador se alimentaram dos cantos e danças para se tornarem outros, mas sem deixar de serem eles mesmos, preservando em cena a ideia de transitoriedade, do entre dois lugares, entre dois seres. A partir do que propõe a dramaturgia do espetáculo (tanto em sua forma quanto em seu discurso, como abordaremos mais adiante), os atores não se fixam na ideia de um personagem, de uma única forma de presença, de ocupação espacial e sonora, transformando-se permanentemente em outros: em cena, ora são pássaros, ora homens, onça, mulher, árvore, fazendeiro, índio e homem branco; coexistem em suas várias formas de vida, ora como narradores, ora como criaturas. Como diz o programa do espetáculo: "Vimo-nos uns aos outros, balagans, devorados pelos Paiter. Eles nos comeram. Estávamos dentro deles. Ou eles dentro de nós?"

Em seu livro a Encenação Contemporânea: origens, tendências, perspectivas, Patrice Pavis elenca algumas montagens que transitam pelo lugar da interculturalidade e lança seu olhar sobre "Muda. Melopeia", de Jean Lambert-Wild. O teórico francês toma tal exemplo como uma amostra de tendências contemporâneas que reduzem a dicotomia entre encenar e performar ao colocarem a direção de atores e a performance no centro do dispositivo da encenação (PAVIS, 2010, p.67). Aqui, faço o paralelo que me parece caber também para a análise do que se estabelece em Recusa. Porém, cabe ressaltar: se Recusa traz elementos que rompem com o dramático, integra-os à sua estrutura não como causa deliberada, mas sim como consequência da procura por novas formas de composição que se aproximassem do pensamento e da estrutura das narrativas mitológicas ameríndias - que, em si próprias, carregam a dualidade e o princípio de dinâmica, exigindo, assim, novas configurações teatrais. 
Não se trata no trabalho da Balagan, assim como no exemplo dado por Pavis, de cair na armadilha da representação, ou da reprodução de um ritual exótico, ou ainda de tentar transpor para o palco uma reconstituição da cultura do outro e restituir sua linguagem original. O mesmo pensamento está expresso na fala de Maria Thaís, durante a entrevista concedida à autora desse texto:

Não queria representar o índio; ele está aí, é uma cultura viva. A representação não dá conta da complexidade, não quero reduzir a cultura a uma única coisa. Os Suruí disseram uma vez para nós: "nosso desafio é que vivemos com não-indígenas e, ao mesmo tempo, nos mantermos indígenas". Isso foi muito determinante para o nosso olhar. Não tem nada aqui no trabalho que reproduza, que seja uma mimese do que vivenciamos lá. O campo da arte é o da absoluta liberdade. Ali tem um patrimônio imaterial, mas eu só posso falar da minha experiência sobre ele, até porque os próprios índios têm boca, voz e inteligência para falarem por eles mesmos sobre o patrimônio. Nesse sentido, artisticamente, não posso fazer senão desta forma. Como tirar de lá e ser outra coisa? Não posso tomar o lugar do outro, senão eu o mato. O outro continua a existir, aí que é o passo que eu aspiro que o espetáculo tenha dado, fazer outra coisa, sermos nós.

\section{"Então foi assim"}

Eduardo Okamoto e Antonio Salvador fazem de seu corpo-voz uma sobreposição de seres e, num fluxo infinito, transformam-se em pacas, aves, cobras, índios, homem branco quase, como quem nega a permanência. Esta "mutação permanente", apresentada desde a cena inicial, servirá de base também a toda a dramaturgia, na qual Luis Alberto de Abreu articula diversas narrativas indígenas, rompendo com a noção de uma construção que se fixa no tempo, emendando uma narrativa à outra, como se a primeira se metamorfoseasse na próxima, constituindo várias formas de vida presentes em um único ser.

Mais uma vez, essa afirmação da coexistência aparece na dramaturgia não só no discurso verbal, mas também na escolha formal da rapsódia, cuja noção, mais que apenas colocar em crise o dramático - sem apoiar-se nas perspectivas da representação, de personagens, de um enredo com início-meio-fim -, consiste no movimento de decompor-recompor, trazendo para o texto seu formato híbrido.

As características da rapsódia, tais como Jean-Pierre Sarrazac as formula, são ao mesmo tempo "recusa do 'belo animal' aristotélico, caleidoscópio dos modos dramáticos, épico, lírico, inversão constante do alto e do baixo, do trágico e do cômico, colagem de formas teatrais e extrateatrais, formando o mosaico de uma escrita em montagem dinâmica, investida de uma voz narradora e questionadora (...) Passando pelo pressuposto da hibridização, do inédito e do entre-dois, preconizando a irregularidade contra a uniformidade e a unidade, a escrita rapsódica não apenas conduz a uma crise salutar do drama, como cria esse espaço privilegiado de confronto e tensionamento onde lutam e se superpõem as formas" (SARRAZAC, 2012, p.153). 
Assim justifica Luis Alberto de Abreu a sua escolha: "Queríamos narradores. Queríamos nos aproximar artisticamente da natureza/cultura ameríndia, tão próxima e tão desconhecida. Queríamos saber como ver o mundo sob a perspectiva do outro, deles", afirma o dramaturgo em texto publicado no programa do espetáculo. É como se a nova temática e a percepção de mundo nela implícita não coubessem em molduras já conhecidas e fosse preciso instaurar uma nova escritura textual e cênica.

A rapsódia, nesse sentido, seria o que Sarrazac define como "teatro dos possíveis, no qual coexistem e se somam os contrários, no qual tudo é colocado sob o signo da polifonia". Essa busca pela polifonia e o rompimento com uma dramaturgia temporal em prol de uma voz rapsódica são concretizados em cena por Recusa, quando este opta em sua constituição pelo constante deslocamento de discursos, buscando estabelecer uma dramaturgia que se inscreve menos no tempo para buscar inscrevê-la no espaço, como explica Maria Thaís em um trecho da entrevista:

\begin{abstract}
Não estamos falando de fragmentação, mas sim de células que existem simultânea e autonomamente. Nesse processo (de criação do espetáculo), um dia falei para o Abreu:" essa dramaturgia é espacial". Disse isso porque a gente ainda estava tentando achar uma organização temporal, constituir um tema que pudesse ficar aproximando o espectador para o reconhecimento. Mas conseguimos, no fim, abrir mão disso. Essas questões artísticas pairam sobre as nossas cabeças há muito tempo: a questão da narratividade, o ator e a performance do corpo e da voz pautam o trabalho desde sempre.
\end{abstract}

"Assim foi, assim é", diz o texto do espetáculo; passado e presente em cruzamento, lacuna temporal. Ao apropriar-se das narrativas mitológicas indígenas e delas fazer também estrutura para a inserção da narrativa contemporânea, Luis Alberto de Abreu desloca o fato real (a "descoberta" de dois índios isolados na floresta) para o plano mítico. Se havia ali um único elemento de identificação com o real (a notícia de jornal), este se transfigura como imagem mítica do par primordial ao final do espetáculo.

Diante de uma certa alteridade "radical", que os povos ameríndios criam e representam, há uma busca por rever estruturas de pensamento em suas próprias bases epistemológicas. É uma outra forma de conhecer, representar e dizer o mundo, e os mitos seriam chaves para acessá-la. "Homem branco quer saber tudo", diz um dos índios certa hora. O desencadeamento das narrativas do mito levaria a um pensamento que redefine as questões de alteridade, ou ainda, segundo a diretora Maria Thaís:

O mito é lacunar, ele deixa brechas para que o espectador crie. E me alinho a esse pensamento de que o espectador é parte da criação. $O$ ator, muitas vezes, acha que tem que dizer tudo, com a palavra, o corpo, a voz. A gente tem uma tendência a representar tudo, a dar uma estrutura que é facilitadora. Por outro lado, a linguagem que o mito traz só se constituiu na lacuna. O teatro é presencial, é onde a alteridade existe de fato, e não posso 
supor que o espectador não tenha capacidade de articulação. O mito me dá essa dimensão também de simultaneidade, de teia, porque o mito não se resolve nele mesmo. E tem, ainda, uma dimensão em termo de escolha de linguagem: eu gosto de coro, de muita gente em cena. "Recusa" mesmo não é monologo porque é, em síntese, a potência da alteridade, porque os dois, o Antonio Salvador e o Eduardo Okamoto, são diferentes mesmo, e a gente conseguiu jogar com isso. Prefiro contar histórias de grupos onde os sujeitos, dentro do grupo, se manifestam. O mito não pertence a um homem específico, mas a muitos.

Através de sua escrita, Luis Alberto de Abreu, ancorado no corpo-voz dos atores, cria uma explosão de vozes, cujo enunciador se embaralha no jogo da metamorfose: homem, que engoliu onça que comeu o padre. Quem fala? O homem? A onça? O padre? Essa transitoriedade do quem enuncia e o que enuncia é ainda mais sintetizada na fala dos atores quando estes não estão na "mesma língua" da plateia: quem fala? O índio em si? O ator? O índio no corpo do ator? O ator no corpo do índio?

\section{"Por quê? Eu sei? Não sei se sei. Quem sabe?"}

Novamente recorrendo a Pavis, o teórico francês localiza na cena teatral contemporânea procedimentos que promovem uma espécie de destinerrância ${ }^{3}$, a qual foi submetida o autor, o encenador e, depois dele, na contemporaneidade, o espectador. Segundo Pavis, a performance pós-moderna estaria habituada a exercer a alteridade à medida que aceita em seu seio diferentes manifestações. Em contrapartida, a encenação, como a conhecemos a partir dos anos 1930, buscaria exercer a autoridade sobre o sentido. O que ele propõe, e é neste lugar que pode se poderia pensar também algumas das proposições presentes em Recusa, é a situação de muitos trabalhos no entre-lugar, da autoridade à alteridade (PAVIS, 2010, p.78-83), indo da encenação à performance e vice-versa. Tal perspectiva pode também ser constatada em outra afirmação da diretora do espetáculo:

A gente faz pesquisa pensando em fazer um espetáculo. Mas não sabemos o que vamos encontrar durante o processo, e o formato daquilo que chamamos de espetáculo podia ser muito diverso do que fizemos em "Recusa". Será que não é só uma performance? Só canto, ou só dança? Ou no campo do rito? Eram perguntas que nós fazíamos durante a pesquisa. Não sabíamos o que fazer. Mas havia uma questão importante: era não fazer um espetáculo com esse material de acordo com o senso básico de teatro, facilitar nesse sentido para o espectador a construção de sentido. Não me refiro apenas a desconstruir o dramático, mas sim, falar de um modo que não supõe se existe o dramático, porque aquele mundo precisaria encontrar uma forma que fosse justa ao material, onde forma e conteúdo ficassem amalgamados.

3 J. Derrida, em Sur Parole.Instantanés philosophiques, p. 53: "Como a morte, a indecidibilidade, o que chamo também de 'destinerrância', a possibilidade para um gesto de não chegar ao destino, é a condição do movimento de desejo, que de outra forma morreria antes do tempo". 
Esse percurso da autoridade à alteridade é feito durante todo o espetáculo. Pud e Puder se comunicam em um dialeto não-identificável pelo espectador. Essa língua só é reconhecida pelos dois e as palavras, as mesmas que em outro momento servem ao "esclarecimento", aqui funcionam como métrica, ritmo, som. Rompe-se, logo no começo, a possibilidade imediata de identificação do espectador, ressaltando o índice performativo, aqui também entendido como uma outra maneira de abrir-se para o outro - o espectador. Ao mesmo tempo, a dramaturgia parece lembrá-lo, em outros momentos, que ele é o outro ao qual se busca acessar incessantemente, como se afirmasse a semelhança possível presente na diferença entre a visão de mundo ameríndia e a ocidental, entre o que se estabelece no palco e o que se estabelece na plateia: "é gente que nem nós", alerta o texto em diversos momentos. Aqui, em Recusa, o espectador é convidado a deslocar-se em um movimento de não mais reconhecer-se em cena, mas, sim, ao outro, o índio metamorfoseado nos corpos e nas vozes dos atores, que "vestiram suas peles".

\begin{abstract}
Tem muita resistência em assistir ao espetáculo, de permitir outra fruição que não aquela que permite a identificação com o que se fala e com o que se vê. A gente percebe as pessoas que olharam e, de cara, não querem aquilo. Outras que não querem, mas se encantam porque tem ali uma performance muito viva e crível acontecendo, na performance dos atores e da cena, tudo muito amalgamado entre ator, texto, música, cenário, reconhecem um valor estético, embora não se deleitem com o que está sendo dito. E aqueles que se comovem no sentido pleno, que a gente não esperava. Na estrutura do teatro que a gente concebe mais tradicionalmente, o espectador deve se reconhecer. Neste trabalho, ele reconhece ao outro, não a ele mesmo, não tem a possibilidade de reconhecimento porque ele não é índio e, muitas vezes, recusa o outro. Chegar nesse resultado, independentemente de qualquer efeito teatral, me leva a uma descoberta de que o teatro não é o reconhecimento e, sim, o encontro com o outro. Encontro com o estranhamento, com o outro, que não se conhece, que não nomeia de imediato.
\end{abstract}

Essa distância entre os pares primordiais no teatro (o que faz e o que vê), em Recusa estabelece-se também como possível metáfora para a distância entre duas visões de mundo, uma espécie de "quarta parede" que pode ser atravessada a qualquer momento. Quando começa a encenação, nada separa de fato esses dois mundos (palco e plateia/ Natureza e Cultura) a não ser a convenção de que não podem se atravessar. Ao mesmo tempo, é sempre para o espectador que estão sendo contadas aquelas histórias.

Porém, com o passar do tempo, palco e plateia começam a ganhar, mesmo que sutilmente, uma barreira física à medida que os galhos de madeira secos vão preenchendo o espaço e que, ao fim, estão entre eles. Numa livre interpretação, arriscaria dizer que quanto mais a encenação reafirma uma outra relação entre Natureza 
e Cultura na estrutura da cena, índio e árvore metamorfoseados em uma só coisa, mais parece reafirmar, através dessa "fronteira natural", a dificuldade do espectador de deslocar-se da sua visão habitual de mundo ocidental. Recusa exige do espectador que este também rompa com a ideia de unidade de formas, discursos, narrativas, ou mais que isso, rompa com a sua forma de enxergar o mundo. E este não é um exercício fácil. Propõe ao público que não resista, e sim se entregue à heterogeneidade, ou, como propõe Jorge Dubatti:

\begin{abstract}
O cânone da multiplicidade exige um espectador "politeísta", capaz de fazerse companheiro em diversos conceitos de teatro (ou bases epistemológicas). Dali a importância da educação do espectador (...). É indispensável formar uma comunidade hermenêutica sustentada na amigabilidade e na disponibilidade, que não impugne ou favoreça determinadas bases epistemológicas, que conceba o teatro em sua amplitude deslimitada e não oriente sua atividade em direção a uma redução hierárquica dos campos teatrais. Uma comunidade horizontal, mas simultaneamente crítica. Há espectadores totalitários e autoritários, espectadores despóticos, tirânicos e sabotadores que - longe da atitude de disponibilidade ou amigabilidade exigem às poéticas o que essas talvez não queiram propor, que - em termos de banquete - rechaçam a comida mexicana porque não tem o sabor da comida francesa" (DUBATTI, 2007, p. 140).
\end{abstract}

Não são os índios que se negaram a aceitar o outro; ao contrário, parece nos dizer o tempo todo o espetáculo, o outro é parte do índio, do que constituiria sua identidade (esta, também, mutável, capaz de se transformar em outras). No mesmo sentido, parece nos provocar o espetáculo, cabe ao espectador estabelecer contato. Em última instância, é ele quem recusa, ou não. 